\title{
Preventive Effects of Yogurt Fortified With Purple Roselle Extract Against Cardiotoxicity in Rats Exposed With 2,3,7,8-tetrachlorodibenzo-p-dioxin
}

\author{
Ani Setianingrum ${ }^{1 *}$, Iffa Fanadila Febriani ${ }^{2}$, Herlina Pratiwi ${ }^{3}$, Ajeng Erika P. Haskito ${ }^{1}$ \\ ${ }^{1}$ Veterinary Public Health Laboratory, Faculty of Veterinary Medicine, University of Brawijaya, Malang, Indonesia \\ ${ }^{2}$ Faculty of Veterinary Medicine, University of Brawijaya, Malang, Indonesia \\ ${ }^{3}$ Veterinary Embryology Laboratory, Faculty of Veterinary Medicine, University of Brawijaya, Malang, Indonesia
}

\begin{abstract}
Dioxin is one of the environment's persistent organic pollutants that harm animal and human health. Prolonged exposure to 2,3,7,8-tetrachlorodibenzo-p-dioxin (TCDD) can disrupt normal organ function including heart. Yogurt is known to have antioxidant properties, and fortification natural plant-based antioxidant purple roselle (Hibiscus sabdariffa $L$ ) extract into yogurt can improve the antioxidant potential. The purpose of this study was to determine the preventive effects of yogurt fortified with purple roselle on dioxin exposure rats (Rattus norvegicus) based on the levels of Malondialdehyde (MDA) and histopathological of the heart. This experimental study used a completely randomized design (CRD). A total of 30 male Wistar rats were divided into five groups (Negative Control, Positive Control, Treatment groups $\mathrm{T} 1, \mathrm{~T} 2$, and $\mathrm{T} 3$ ), a dose of $200 \mathrm{ng} \cdot \mathrm{kg}^{-1} \mathrm{BW}$ TCDD and $1 \mathrm{~mL}$ of roselle yogurt $0.5 \%, 1.0 \%$, and $1.5 \%$ were given orally for 12 days. MDA levels were analyzed using the Thiobarbituric Acid (TBA) assay and histopathology of the heart using the Haematoxylin Eosin (HE) staining method. Statistical analysis used one-way Analysis of Variance (ANOVA). Histopathology changes were analyzed descriptively. The results showed that TCDD exposure induced oxidative stress in heart tissue, and yogurt roselle has the potential to prevent an increase of MDA levels significantly $(p<0.05)$. Furthermore, TCDD can cause histopathological alterations, such as necrosis and hemorrhage, and yogurt roselle was proven to prevent cardiotoxicity due to TCDD exposure.
\end{abstract}

Keywords: heart, histopathology, MDA, purple roselle, TCDD, yogurt.

\section{INTRODUCTION}

Development in Industrial activities is often followed by an increasing level of pollution to the environment. One of the pollutants that are considered toxic and produced by human activities is dioxins and their congeners. Due to the toxic, persistent, bioaccumulative nature of dioxins in the environment, the United Nations of Environmental Program (UNEP) is actively campaigning on the problem of dioxin pollution so that it has become a global concern [1]. Dioxins congener that have the highest toxicity is 2,3,7,8 -Tetrachlorodibenzo-p-dioxin (TCDD). In humans and laboratory animals, TCDD induced carcinogenesis, teratogenicity, reproductive toxicity, hepatotoxicity, endocrine disruption, wasting syndrome, and immunological dysfunction [2,3].

The aryl hydrocarbon receptor (AhR) pathway, which induces cytochrome P450 and other drug-metabolizing enzymes, can explain the toxicity of TCDD. Cardiotoxicity manifestations due to dioxins exposure include ischemic heart disease and an increase in blood pressure. In addition, cardiac tissue damage

\footnotetext{
${ }^{*}$ Correspondence address:

Ani Setianingrum

Email : ani.setia@ub.ac.id

Address: Faculty of Veterinary Medicine, Brawijaya University Malang, 65151, Indonesia
}

caused by dioxin intoxication includes hemorrhage and necrosis $[2,4]$. Some in vivo investigations suggest that TCDD exposure has serious consequences for the cardiovascular system [5]. Chronic TCDD exposure caused degenerative cardiovascular diseases in rats, including cardiomyopathy and chronic active arteritis. Furthermore, TCDD accelerates the production of reactive oxygen species (ROS), which causes lipid peroxidation, cell membrane damage, DNA and protein damage at the cellular level. TCDD was found to cause oxidative stress in various organs [2]. Studies suggested that using antioxidant supplementation possible to counteract the adverse effect of TCDD toxicity.

Yogurt is a dairy product that has many health benefits due to its potent antioxidant activity. Milk proteins have shown antioxidant activity for the scavenging of reactive oxygen species [6]. Casein derived from yogurt can inhibit the lipoxygenase-catalyzed lipid autoxidation and increased superoxide dismutase (SOD) enzyme activity [7]. Furthermore, whey proteins can efficiently inhibit lipid oxidation [8]. Bioactive peptides are released from milk proteins by enzymatic breakdown during the fermentation of milk by lactic acid bacteria. These peptides have immunomodulatory activity, ACE inhibitory, antimicrobial, and antioxidative activity [9]. Fortification of yogurt with plant extracts that is rich in natural antioxidants is applied to improve 
against Cardiotoxicity in Rats (Setianingrum, et al.)

the nutritional and therapeutic quality of yogurt. One of the natural plant-based antioxidants is purple roselle flowers (Hibiscus sabdariffa L.). Roselle has been shown to have the capacity as an antioxidant due to the presence of components such as anthocyanins, vitamin C, flavonoids, and phenolic acids [10]. Natural plantbased antioxidants can be used to reduce the free radical formation and increase antioxidant capacity, as well as to substitute synthetic antioxidants that have adverse effects, such as liver damage and carcinogenesis [11].

This study aims to investigate the effect of yogurt fortified with purple roselle extract on the cardiotoxicity caused by $2,3,7,8-\mathrm{TCDD}$ exposure. The protective effect of yogurt fortified with purple roselle extract was observe based on the level of malondialdehyde (MDA) and the histopathological changes of the cardiac tissue.

\section{MATERIAL AND METHOD \\ Chemicals}

Commercial cow's milk, purple roselle, Yógourmet ${ }^{\circ}$ yogurt starter containing three strains lactic acid bacteria $L$. bulgaricus, $S$. thermophilus and L. acidophilus, corn oil, 2,3,7,8TCDD (purity>99\%) Supelco, Cat No: 48599, dried purple roselle (Hibiscus sabdariffa $L$ ) calyx from a local supplier, East Java, Indonesia. We also used distilled water, $10 \%$ formaldehyde, $70 \%$ ethanol, $80 \%$ ethanol, $90 \%$ ethanol, HE dyes, and paraffin.

\section{Making of Purple Roselle Extract}

The dried roselle flowers were finely ground into flour, sieved using a 60-mesh sieve. The roselle flower flour was dissolved in water with a ratio of $20 \mathrm{~g}$ : $100 \mathrm{~mL}$, pasteurized at $63-65^{\circ} \mathrm{C}$ for 30 minutes. The liquid was then carefully separated from the sediment [12].

\section{Making Yogurt Fortification With Purple Roselle Extract}

Fresh cow's milk was pasteurized at $72^{\circ} \mathrm{C}$ for 15 seconds, then cooled down until the temperature reached $45^{\circ} \mathrm{C}$. Yogurt starters were inoculated (3\%), homogenized, then incubated at $45^{\circ} \mathrm{C}$ for 4 hours until the liquid starter reaches a $\mathrm{pH}$ of 4.5-5. The plain yogurt was then separated into different bottles and fortified with different concentrations of purple roselle extract, $0.5 \%$, $1 \%$, and $1.5 \%$. The mixture was homogenized and stored at $4^{\circ} \mathrm{C}$ until used.

\section{Animals and Treatment}

A total of 30 white male adult Wistar rats (Rattus norvegicus) were obtained from Experimental Animal Institute, LPPT UGM,
Indonesia. The animal was placed in group rat cages in 12-h light-dark cycle at room temperature of $25-26^{\circ} \mathrm{C}$. Acclimatization to the laboratory environment was carried out for seven days. Standard commercial rat pellet and water were given ad libitum. The experiment was approved by the Institutional Ethics Committee of Brawijaya University number 1123-KEP-UB. Rats were randomly divided into five groups. Negative control (NC) group, given only distilled water by gavage. Group positive control (PC), TCDD in corn oil was administered orally with doses of 200 ng. kg-1 BW daily. Treatment groups were given TCDD and yogurt fortified with purple roselle extract. Group T1 (TCDD $+0.5 \%$ roselle yogurt); group T2 (TCDD + 1\% roselle yogurt); group T3 (TCDD $+1.5 \%$ roselle yogurt).

The experiment was conducted for 12 days. The animals were then euthanized to collect heart tissues. The heart organ was divided into two parts, one part was stored in $10 \%$ formaldehyde solution for histopathology analyses, and the other part was stored at $-80^{\circ} \mathrm{C}$ for biochemical analysis.

\section{Tissue Malondialdehyde (MDA) Analysis}

The examination of MDA levels was carried out by measuring Thiobarbituric acid reaction [13]. Heart tissue was cut into small pieces and weighed 0.1 gram, and then crushed. Furthermore, the homogenization process was carried out by centrifuge at a speed of $1000 \mathrm{rpm}$ for 10 minutes. The resulting supernatant was then measured for absorption using a spectrophotometer at $\lambda=532 \mathrm{~nm}$.

\section{Histopathological analysis}

For microscopic evaluation, heart samples were immersed in $10 \%$ formaldehyde solution as a fixation agent. The heart tissue samples were processed by routine tissue technique and were embedded in paraffin. Paraffin blocks are then collected, cut, and placed on a glass object, then dripped with Canadian balm and covered with a glass cover. After that, the glass object was put into the incubator at $37^{\circ} \mathrm{C}$ one night. Then, the preparations were ready for Hematoxylin-Eosin (HE) staining.

\section{RESULT AND DISCUSSION \\ MDA Level From Heart Tissue}

The malondialdehyde (MDA) assay of the heart shows in Table 1. MDA levels from groups with TCDD exposure showed an increase compared to the negative control (NC) group. A significant difference accured between the negative control group compared to the positive 
control group. Treatment groups given with yogurt fortified purple roselle extract (T2 and T3) show a significant decrease of MDA level compared to the positive control (PC) group.

Table 1. MDA level of rat's heart of all group in the study

\begin{tabular}{lc}
\hline \multicolumn{1}{c}{ Groups } & $\begin{array}{c}\text { MDA level (ng. } \mathbf{m L}^{-\mathbf{1}} \text { ) } \\
\pm \text { SD }\end{array}$ \\
\hline Negative Control (NC) & $262.62 \pm 6.60^{\mathrm{a}}$ \\
Positive Control (PC) TCDD & $297.60 \pm 8.85^{\mathrm{c}}$ \\
T1 (TCDD + 0.5\% roselle yogurt) & $276.89 \pm 1.20^{\mathrm{ab}}$ \\
T2 (TCDD + 1.0\% roselle yogurt) & $289.11 \pm 1.57^{\mathrm{bc}}$ \\
T3 (TCDD + 1.5\% roselle yogurt) & $274.71 \pm 6.77^{\mathrm{ab}}$ \\
\hline
\end{tabular}

Note: The different superscript indicates a significant difference $(p<0.05)$ between groups

MDA is formed from biochemical processes in the body as a consequence of lipid peroxidation. TCDD is known to induced toxic responses and increasing oxidative stress. Exposure to TCDD triggers the formation of Reactive Oxygen Species (ROS), lipid peroxidation, and oxidative stress has been indicated as factors leading to acute toxicity of TCDD [14]. In the current study, the MDA level increased in heart tissue which was induced by TCDD exposure, and yogurt fortified purple roselle extract at concentration $1.5 \%$ decreases the heart MDA level close to normal control levels.

TCDD exposure was found to cause considerable lipid peroxidation in cardiac tissue, as well as an increase in MDA levels. The peroxidation of fatty acids by reactive oxygen radicals produced MDA. Malondialdehyde is an indicator of lipid peroxidation and causes irreparable cell damage. Many disorders, including cardiovascular disease, are caused by TCDD-induced oxidative stress, which is defined as an imbalance between free radicals and the antioxidant state [5]. On the other hand, it was discovered that a therapy of yogurt fortified with purple roselle extract was able to protect against oxidative damage caused by TCDD by lowering MDA levels in cardiac tissue.

Yogurt and milk are the most consumed dairy products that have long been known to have health benefits, particularly in the case of yogurt, where the benefits are linked to gut health. The antioxidant capabilities of casein and whey proteins in yogurt are apparently due to their ability to bind transition metals and scavenge free radicals [15]. This study used three lactic acid bacteria $L$. bulgaricus, $S$. thermophilus, and $L$. acidophilus, as the yogurt starter. Some lactobacilli possess antioxidation activity and can reduce the risk of ROS accumulation during the ingestion of food. Lactic acid bacteria are able to degrade the superoxide anion and hydrogen peroxide $[8,16]$.

Purple roselle calyxes are the source of natural bioactive molecules such as polyphenols and flavonoids, which have shown antioxidant potential. Fortification of yogurt with roselle extract has proven to improved antioxidant activity [17]. Fortification of purple roselle extract into yogurt with a concentration of $1.5 \%$ has the best activity in preventing oxidative stress induced by TCDD, hence preventing the lipid peroxidation to increase. Bioactive peptides in fermented milk can stabilize radicals by donating hydrogen atoms. Radicals are captured by bioactive peptides of the yogurt. Thus, it prevents the initiation of the formation of lipid radicals which are unstable because they lose one hydrogen atom from the lipid molecule. Hibiscus sabdariffa $L$ contains anthocyanin with high antioxidant activity. Anthocyanins are believed to be the active components responsible for the antihypertensive and hypocholesterolemic effects [10].

\section{Heart histopathology results}

Figure 1 shows the heart histopathology of rats (Rattus norvegicus) from negative and positive control groups. Hematoxylin Eosin (H\&E) stained sections of $\mathrm{c}$ left ventricle revealed a normal structural architecture of cardiomyocytes. Cardiac histopathology in the negative control group showed no significant tissue damage, there was a central cell nucleus, pink cytoplasm, and clear boundaries between cells. A normal picture of heart cells stained with H\&E shows regular cardiac muscle fibers, clear boundaries between cells, and one or two nuclei in the center of the cell.

All treatment groups showed changes in heart muscle cells in the form of myocyte cells that experienced necrosis and hemorrhage in the myocardium. Histopathological damage was seen in the Positive Control (PC) group. The prominent changes consist of myocyte cell necrosis, hemorrhage, and extravasation of red blood cells between myocytes (Fig. 2B, 2B1). The PC group was exposed to TCDD as a toxic substance. Continuous administration of TCDD can induce damage to the heart tissue. The many foci of myocardial degeneration found in the rat heart were characteristic of the look of cardiomyopathy $[2,5,18]$. Apoptosis was indicated by the presence of pyknotic myonuclei 

against Cardiotoxicity in Rats (Setianingrum, et al.)

and dark eosinophilic cytoplasm in certain cardiomyocytes. Cardiomyopathy can occur as a result of anoxia caused by vascular alterations or as a result of direct damage to cardiac cells.

TCDD exposure to rats (Rattus norvegicus) will trigger an increase in Reactive Oxygen Species (ROS) in the heart. ROS bind to $\mathrm{H}$ atom molecules derived from lipids, proteins, and nucleotides contained in DNA and cell organelles, so that DNA and cardiac organs experience dysfunction and structural damage. Damage to cell protein structure and damage to cardiac cell organelles caused by ROS is the basic pattern of necrosis. High levels of ROS can cause damage and cell death $[2,5]$.

TCDD toxin that enters the body will inhibit blood clotting so that it damages the endothelium of blood vessels. Damage to the walls of blood vessels causes blood to escape from the circulation, resulting in hemorrhage
[18]. The occurrence of hemorrhage can occur because high ROS are not inhibited effectively by endogenous antioxidants. Group T1 (TCDD and yogurt roselle $0.5 \%$ ) showed myocyte cells with pyknotic necrosis accompanied by hemorrhage (Fig. 1C, C1).

Group T2 (TCDD and yogurt roselle 1.0\%) shows necrosis of myocyte cells and irregular myofibril structures and is still accompanied by hemorrhage (Figure 1D, D1). Group T3 (TCDD and yogurt roselle $1.5 \%$ ) showed that myocyte cells underwent necrosis, which was slightly accompanied by the presence of hemorrhage. However, the myofibril structure in the T3 group was seen to be organized and similar to the NC group (Fig. 1E, E1). The accumulation of free radicals in the heart will stimulate lipid peroxidation. Lipid peroxidation will cause damage to cell membranes and heart structures.
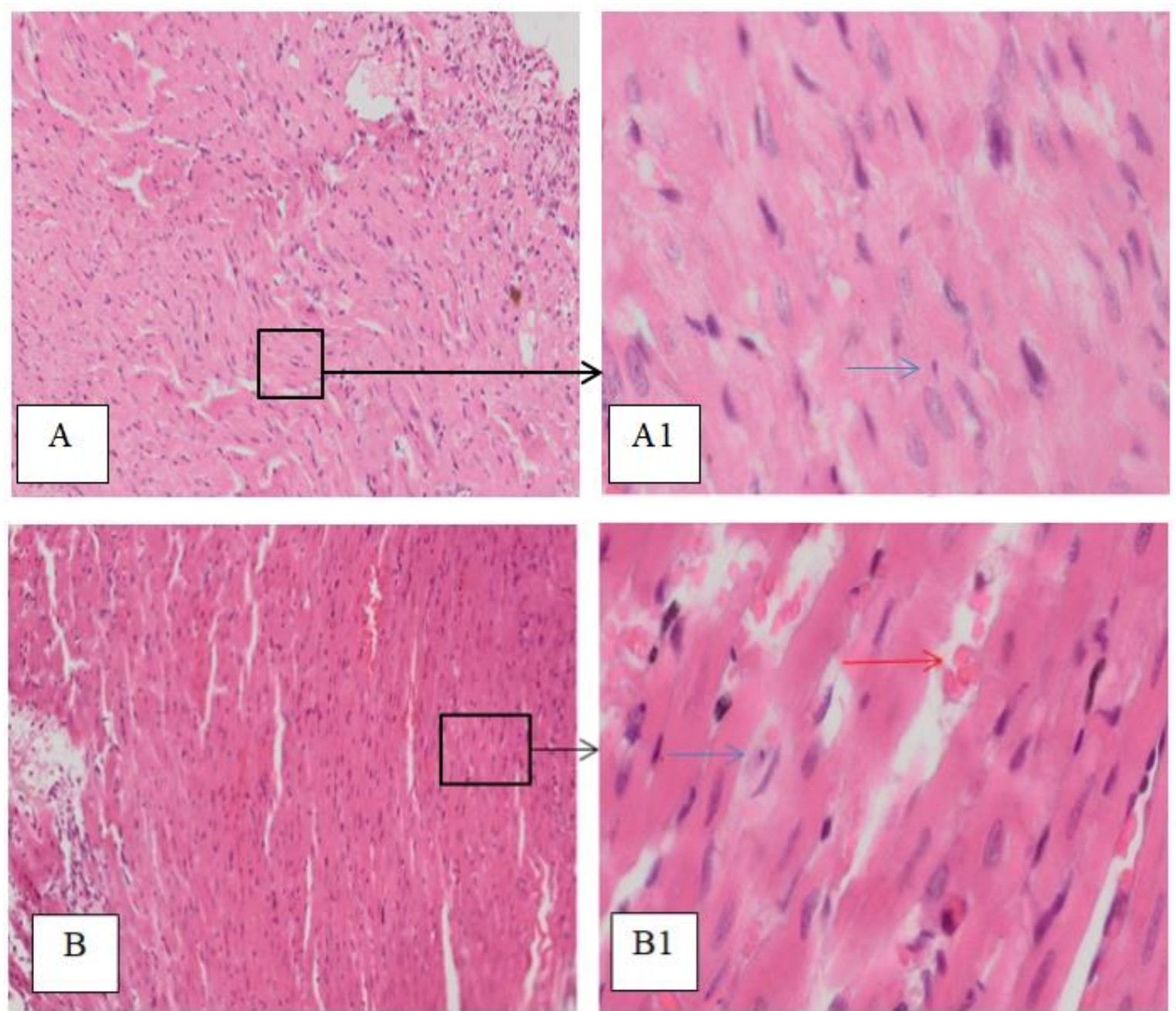

Figure 1. H\&E stained sections of the left ventricular myocardium of control groups. A. Negative Control (NC) group (A: magnification 100x, A1: magnification 400x); B. Positive control (PC) group (B: blue arrow: necrosis; red arrow: hemorrhage 

against Cardiotoxicity in Rats (Setianingrum, et al.)

Cardiac histopathology results in the T3 group were better and gave an optimal effect than the $\mathrm{T} 2$ and $\mathrm{T} 1$ groups. The mechanism in preventing the occurrence of histopathological damage to myocyte cells undergoing necrosis through the antioxidant activity of yogurt fortified with purple roselle extract is to donate $\mathrm{H}$ atoms to free radicals so that free radicals will be stable. Bioactive peptides in fermented milk will stabilize radicals and prevent further damage to cardiac cells. Anthocyanin and other phenolic compounds present in purple roselle extract play a role in increasing antioxidant activity $[10,11]$.
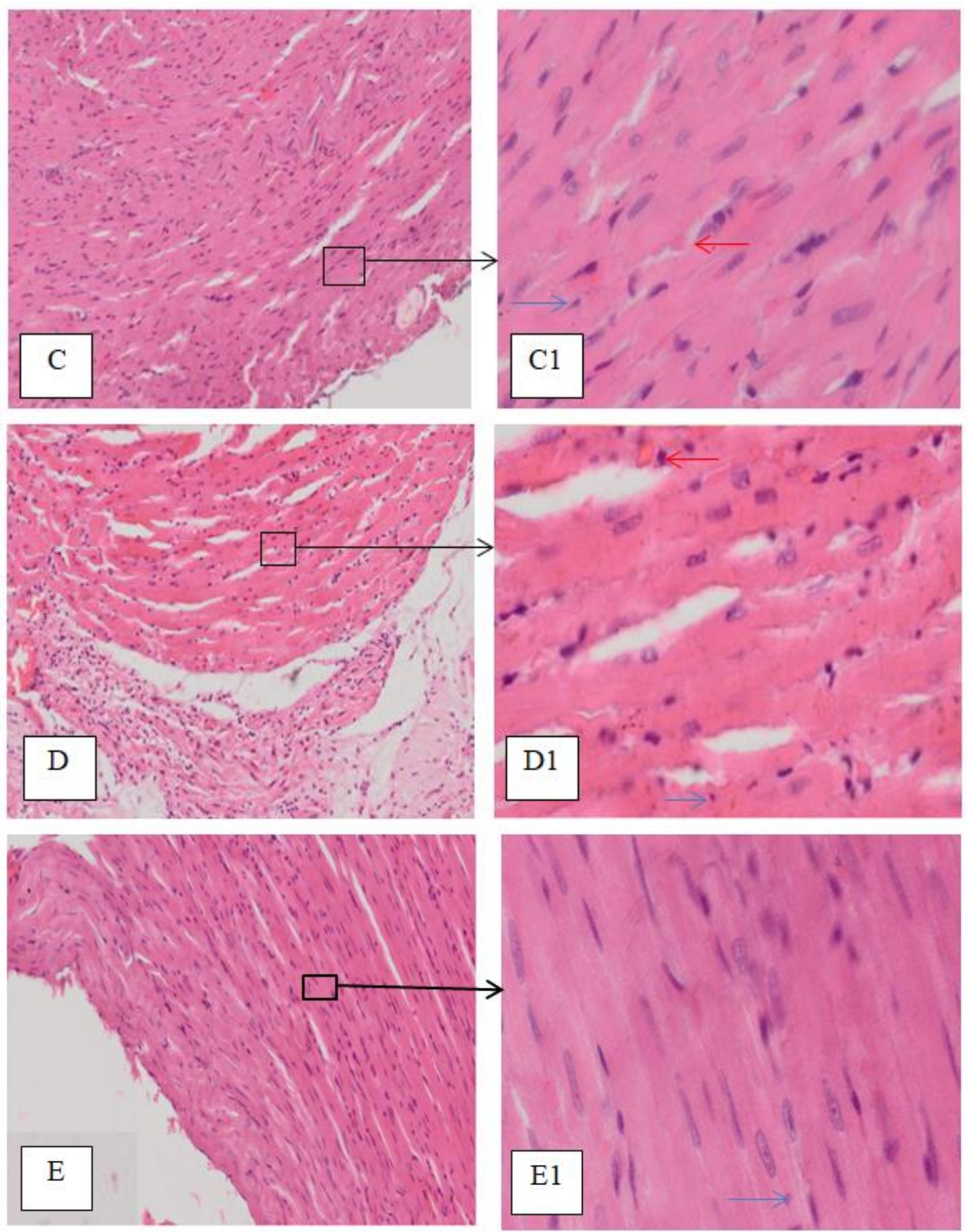

Figure 2. H\&E stained sections of left ventricular myocardium of treatment groups. C. T1 group (TCDD $+0.5 \%$ roselle yogurt) C: magnification 100x, C1: magnification 400x; D. T2 group (TCDD + 1\% roselle yogurt) D: magnification 100x, D1: magnification 400x; E. T3 group (TCDD + 1.5\% rosele yogurt) E: magnification 100x, E1: magnification 400x; blue arrow: necrosis; red arrow: hemorrhage 
against Cardiotoxicity in Rats (Setianingrum, et al.)

According to the results, yogurt fortified with roselle extract enhanced antioxidant activities and cell viability. It proves that the antioxidants in yogurt fortified with purple roselle extract play a role in stabilizing reactive free radicals, so that tissue damage can be prevented.

\section{CONCLUSION}

Based on the present study results, it can be concluded that giving yogurt fortified with purple roselle extract with concentrations of 0.5 and $1.5 \%$ was potential in preventing increasing malondialdehyde (MDA) and preventing histopathological damage levels of rat heart (Rattus norvegicus) that have been exposed to TCDD. Thus, yogurt fortified with purple roselle extract, which decreases oxidative stress, could be a promising anti-TCDD toxicity option.

\section{CONFLICT OF INTEREST}

The authors have no conflicts of interest that are relevant to this article.

\section{ACKNOWLEDGEMENT}

This study was supported by research funding from the University of Brawijaya. The authors thank LPPM UB, Biosains Institute UB, and Faculty of Veterinary Medicine UB.

\section{REFERENCES}

[1] United Nations of Environmental Programme. 2008. The 12 initial POPs under the Stockholm Convention. Available at: http://chm.pops.int/TheConvention/ThePO Ps/The12InitialPOPs/tabid/296/Default.aspx

[2] Ciftci, O., A.S. Duman, N.B. Turkmen, A. Taslıdere. 2018. Beta-glucan prevents toxic effects of 2,3,7,8-TCDD in terms of oxidative and histopathological damage in heart tissue of rats. Brazilian J. Pharm. Sci. 54(3). 1-7.

[3] Setianingrum, A., G.D. Satria, M.C. Padaga. 2019. Aktivitas antioksidan kasein yogurt susu kambing pada fungsi hati tikus model intoksikasi dioksin. Vet. Biomed. Clin. J. 1(1). 26-32.

[4] Yoshioka, W., C. Tohyama. 2019. Mechanisms of developmental toxicity of dioxins and related compounds. Int. J. Mol. Sci. 20(3). 617. DOI: 10.3390/ijms20030617.

[5] Ciftci, O., O.M. Disli, N. Timurkaan. 2012. Protective effects of protocatechuic acid on TCDD-induced oxidative and histopathological damage in the heart tissue of rats. Toxicol. Ind. Health. 29(9). 806-811.
[6] Dziuba, B, M. Dziuba. 2014. Milk proteinsderived bioactive peptides in dairy products: molecular, biological and methodological aspects. Acta Sci. Pol. Technol. Aliment. 13. 5-25.

[7] Setianingrum, A., A.E.P. Haskito. 2021 Antioxidant activity of casein yogurt against dioxin toxicity in rats liver. IOP Conference Series: Earth and Environmental Science. 762(012056).

[8] Brandelli, A., D.J. Daroit, A.P.F. Correa. 2015. Whey as a source of peptides with remarkable biological activities. Food Res. Int. 73. 149-161.

[9] Mohanty, D.P., S. Mohapatra, S. Misra, P. Sahu. 2016. Milk-derived bioactive peptides and their impact on human health - A review. Saudi J. Biol. Sci. 23(5). 577-83.

[10] Izquierdo-Vega, J.A., D.A. Arteaga-Badillo, M. Sánchez-Gutiérrez, J.A. MoralesGonzález, N. Vargas-Mendoza, C.A. GómezAldapa, et al. 2020. Organic acids from Roselle (Hibiscus sabdariffa L.)- A brief review of its pharmacological effects. Biomedicines. 8(5). 1-16.

[11] Alenisan, M.A., H.H. Alqattan, L.S. Tolbah, A.B. Shori. 2017. Antioxidant properties of dairy products fortified with natural additives: A review. J. Assoc. Arab Univ. Basic Appl. Sci. 1-7.

[12] Noviatri, A, A. Setianingrum, A.E.P. Haskito. 2020. Organoleptic properties evaluation of purple Hibiscus sabdariffa $L$ (Roselle) calyx extract-fortified yogurt. J. Phys. Conf. Ser. 1430(1). 8-13.

[13] Ohkawa, H., N. Ohishi, K. Yagi. 1979. Assay for lipid peroxides in animal tissues by thiobarbituric acid reaction. Anal. Biochem. 95(2). 351-8.

[14] Vijaya, V., P. Palaniswamy, K. Selvi. 2014. Protective effect of ellagic acid against TCDD-induced renal oxidative stress: Modulation of CYP1A1 activity and antioxidant defense mechanisms. Mol biol Rep. 41. 4223-4232.

[15] Farvin, K.H.S., C.P. Baron, N. Skall, J. Otte, C. Jacobsen. 2010. Antioxidant activity of yoghurt peptides: Part 2 - Characterisation of peptide fractions. Food Chem. 123(4). 1090-1097.

[16] Fernandez, M.A., É. Picard-Deland, M. Le Barz, N. Daniel, A. Marette. 2017. Yogurt and health. In: Frias, J., C. MartinezVillaluenga, E. Peñas (Eds). Fermented foods 
in health and disease prevention. Academic

Press. Boston. 305-338.

[17] Suharto, E.L.S., I.I. Arief, E. Taufik. 2016. Quality and antioxidant activity of yogurt supplemented with roselle during cold storage. Media Peternak. 39. 82-89.

[18] Wahba, N.S., M.G. Amer, R.A. Karam, R.H. Mohamed. 2012. Pathology effect of persistent organic pollutants (dioxins) on rat myocardium and amelioration with antioxidant vitamins (role of aryl hydrocarbon receptors and cytochrome P450). J. Clin. Exp. Pathol. 2(7). 130. DOI: 10.4172/2161-0681.1000130.

[19] Birnbaum, L.S. 2017. Dioxin and the $A H$ receptor: Synergy of discovery. Curr. Opin. Toxicol. 2. 120-123.

[20] Ambolet-camoit, A., C. Ottolenghi, A. Leblanc, M. Ji, N. Cagnard. 2015. Two persistent organic pollutants which act through different xenosensors (alphaendosulfan and 2,3,7,8 tetrachlorodibenzop- dioxin) interact in a mixture and downregulate multiple genes involved in human hepatocyte lipid and glucose metabolism. Biochimie. 116. 79-91. 